\title{
In the Time of Corona
}

The whole world has not experienced such a pandemic in the last hundred years since the Spanish flu. COVID-19 disease is a nightmare for mankind. We have now been plunged into a deep sea; wave after wave passing by. The scourge of COVID-19 disease will continue for a long time to come. New changes are taking place at every level of socio-economic and political life, not just in the health sector. Human civilization is in crisis today. The effect of any catastrophic epidemic on human being inevitably affects doctors, nurses, health care workers and health sector, as a whole. Preparations for the pandemic are never complete. As a result, all countries of the world whether rich or poor, developed or underdeveloped are suffering alike.

The first case of this virus was detected in Bangladesh on 8 march 2020 and the first death occurred on 18 march 2020. We are now at the top of third wave. Almost one million people were detected among them more than fourteen thousand patients has died till June 30, 2021.

Bangabandhu Sheikh Mujib Medical University has been trying its best since the beginning of this pandemic to give direction to the nation. Fever clinic and tele-medicine have been providing services across the country. The University has launched holistic medical system for the treatment of COVID-19 patients. With the help of electronic media, our University aired COVID-19 related program each night for months together.

COVID-19 treatment guidelines has been formulated which is easy to understand for the proper management of the patient. Training of physicians, nurses and health care workers is ongoing. University's vaccination Centre has already been garnered with praise from all the corners of the community.
Development is inextricably linked with research in the developed world. We also need to focus more on research related to COVID-19. Gene sequencing, production of different types of mono and poly clonal antibodies and to produce new vaccine in the country is the top most scientific priority. We hope to move forward with the appropriate policy level direction and technical support for our young researchers.

Tackling pandemic is not an isolated job for one person or institution. It requires a concerted effort. All concerned stake holders must give their maximum effort. It is not possible to win this war without involving people from all socio-cultural, economic, religious and political arena.

Meticulous planning, upgraded research and providing state of the art service to the needy health service seekers is our top priority at this hour. Blessings from the Almighty and guidance from our Honorable Prime Minister will help us in this ongoing battle.

This issue of Bangabandhu Sheikh Mujib Medical Journal is a special one where recent COVID-19 related articles and research works are compiled. We will publish more special issues in the coming days. Personal safety, congenial workplace atmosphere and secured nation matters more.

\section{Professor Dr Md Sharfuddin Ahmed}

Vice-Chancellor

Professor and Chairman, Department of Community Ophthalmology

Bangabandhu Sheikh Mujib Medical University (BSMMU)

Dhaka, Bangladesh 